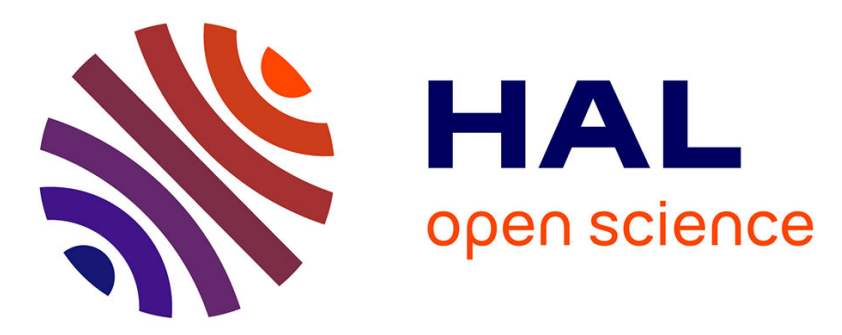

\title{
AN INTEGRATED SYSTEM FOR COLLECTION AND PROCESSING OF ANALYTICAL AND IMAGE DATA FROM THE SEM/STEM
}

J. Mccarthy, J. Benson

\section{- To cite this version:}

J. Mccarthy, J. Benson. AN INTEGRATED SYSTEM FOR COLLECTION AND PROCESSING OF ANALYTICAL AND IMAGE DATA FROM THE SEM/STEM. Journal de Physique Colloques, 1984, 45 (C2), pp.C2-215-C2-218. 10.1051/jphyscol:1984247 . jpa-00223960

HAL Id: jpa-00223960 https://hal.science/jpa-00223960

Submitted on 1 Jan 1984

HAL is a multi-disciplinary open access archive for the deposit and dissemination of scientific research documents, whether they are published or not. The documents may come from teaching and research institutions in France or abroad, or from public or private research centers.
L'archive ouverte pluridisciplinaire HAL, est destinée au dépôt et à la diffusion de documents scientifiques de niveau recherche, publiés ou non, émanant des établissements d'enseignement et de recherche français ou étrangers, des laboratoires publics ou privés. 


\title{
AN INTEGRATED SYSTEM FOR COLLECTION AND PROCESSING OF ANALYTICAL AND IMAGE DATA FROM THE SEM/STEM
}

\author{
J.J. McCarthy and J.P. Benson \\ Tracor Northerm, Inc., 2551 West Beltine Highaway, Middleton, \\ Wisconsin 53562, U.S.A.
}

Résumé - Ce papier décrit un système géré par ordinateur qui donne la possibilité de traiter simultanément la microanalyse, le contrôle de l'instrument et I'analyse d'images en mode SEM ou STEM.

Abstract - This paper describes a computer-based system that provides the capability to integrate microanalysis, instrument control, and image processing for SEM and STEM.

Three important applications of on-line digital computers to electron microscopy have emerged in the last decade; 1) microanalysis by spectral data acquisition and processing; 2) control of instrument parameters; and 3) image processing and analysis. The first two applications have become quite routine due to the development of the minicomputer-based multichannel analyzer (MCA) and the associated interfacing techniques. Since image processing requires manipulation of large amounts of image data, this application traditionally has been pursued only by researchers with access to off-line computer systems. Minicomputer and microcomputer systems have become available which provide (at a reasonable cost) sufficient memory, peripheral storage, display devices, and computational speed to permit on-line acquisition, storage, and processing of image data from the electron microscope. These developments offer the exciting opportunity to characterize specimens by integrating analytical microanalysis, image processing and image analysis in a single, on-line interactive data processing system. This paper describes such a system.

\section{SYSTEM DESCRIPTION}

The system is based upon the TN-5500 computerized multichannel analyzer. The TN-5500 incorporates a DEC LSI-11/23 as the main CPU, and a number of microprocessor-based sub-units. A simplified block diagram is presented in Figure 1.

The CPU monitors and controls the other system components and processes analytical and image data. Up to 4 megabytes of RAM memory may be used for computations, or programs, for storage of spectral or image data. Permanent storage is available via the floppy disks, Winchester hard disk, or removable platter hard disks.

The color video monitor contains a 512 by 256 by 8-bit image memory, and several programmable hardware lookup tables for color selection. Any pixel may be assigned one of 256 colors, selected from a palette containing in excess of a quarter-million color hues. This ability provides great flexibility in the generation of pseudo-color elemental and video images, but also permits micrograph quality continuous-tone (64 gray levels) images to be viewed on the display separately or in combination with color graphics and pseudo-color images. The display format is also quite flexible. Two 256 by 256 by 8 -bit images can be seen side-by-side or in a split screen mode with different color scales. A dual magnification image display with pan and zoom about the cursor position is another useful display format.

The digital scan generator positions the electron beam with 12-bit accuracy in either fast raster or programmed position modes. Video signals are conditioned and then digitized by a fast 8-bit analog-to-digital converter (ADC). Image data may be averaged on a pixel-by-pixel basis, and an entire line can be collected before transfer to the CPU for storage or processing. 


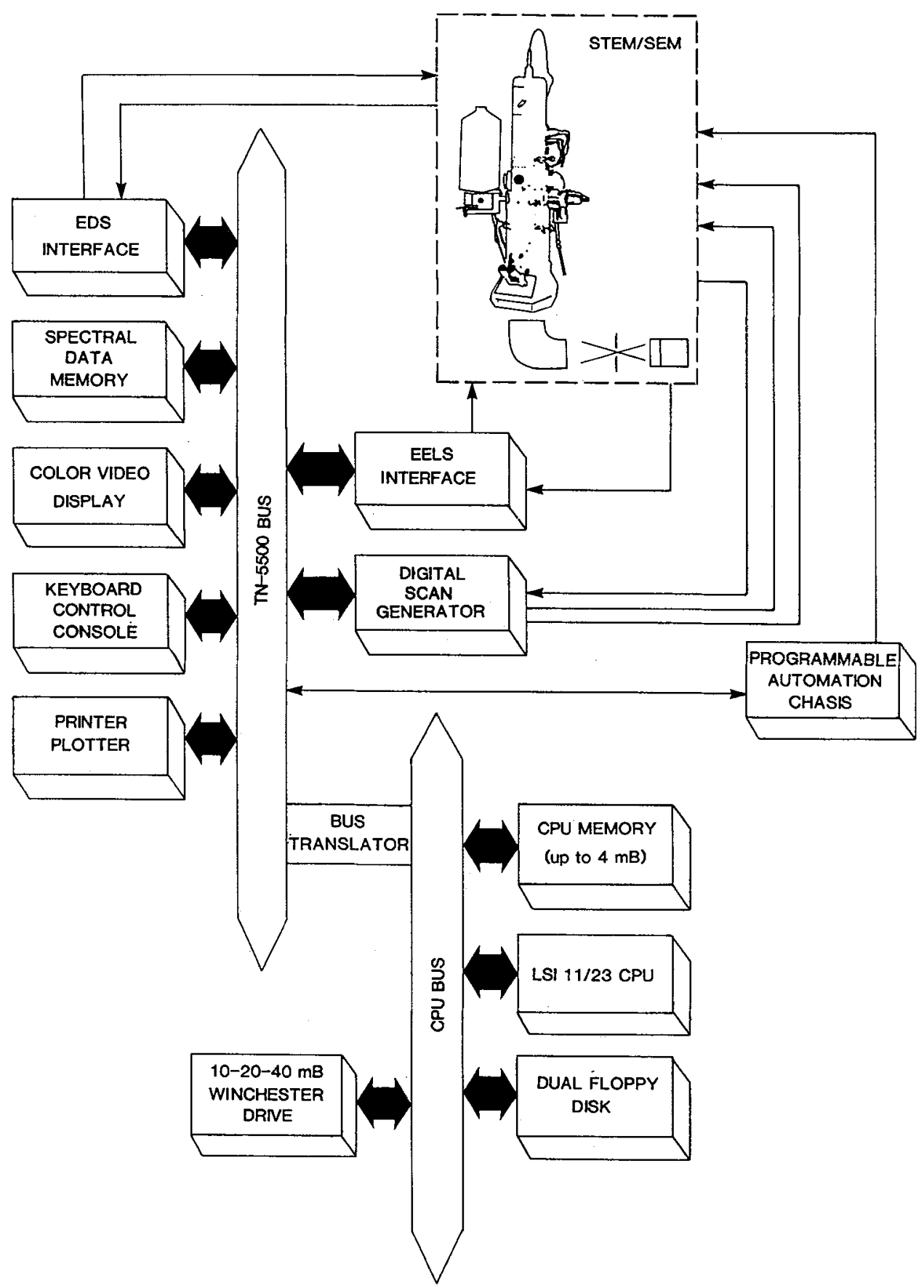

Fig. 1 - Block diagram of the TN-5500 system. Each of the modules on the TN-5500 bus contains one or more microprocessor(s). Functions of principal modules are discussed in the text. 
The EDS and EELS interfaces provide both spectral and image pixel data to the CPU. Spectral data is routed directly to a $4 \mathrm{~K}$ channel, 24-bit data memory, while pixel data is transferred to the CPU on a pixel-by-pixel or image line basis. The EDS interface microprocessor provides continuous zero energy stabilization, system resolution checks, and program control of the pulse processor. The EELS interface contains 8 scaler inputs and a variety of input and output control signals. Two high performance $(>50 \mathrm{MHz})$ scalers are available for EELS data collection. The controls signals will interface to most common spectrometers. When not used for EELS, the microprocessor in this interface can function as an X-ray dot mapping enhancer, ratemeter, or general purpose multichannel scaling (MCS) input.

Control of instrumental parameters and automation of various motor driven devices (WDS, stage axes) is accomplished by the programmable automation chassis. This unit contains its own microprocessor for control and display functions, and additional modules for digital and analog input and output, stepper motor control and scaler/timers for WDS systems.

\section{SELECTED APPLICATIONS FOR SEM/STEM}

\section{Automated Microanalysis}

The tedium of manual point-to-point microanalysis can be eliminated by use of the digital scan generator or automated stage. For example, a quantitative composition profile can be readily obtained. At each point, the beam or stage is stepped a discrete amount, and an X-ray spectrum collected, while the previous spectrum is processed. Net intensity of k-ratio results are stored after each point. At the end of data collection, the stored data can be recalled for further processing including matrix corrections, averaging and statistical analysis, or plotting on the video display.

\section{Image Processing}

Enhancement of selected features of an image can be readily accomplished by a variety of transformations (both linear and non-linear) of the gray levels in the image, or by processing the image with selected filter operators. In addition to the standard logarithmic and gamma gray scale transforms, the system permits a variety of non-linear transforms to be constructed by manipulation of the gray-scale histogram. The effect of each transform can be viewed in real-time on the display. Several operators, including low pass (nearest-neighbor smoothing), gradient, Laplace and Sobel filters, can be applied to an image. A typical filtration of a 256 by 256 pixel image takes 30 to 60 seconds. More traditional operations such as image segmentation to produce binary images, erosion and dilation are also available. Examples of these techniques have been discussed in a previous publication $/ 1 /$.

\section{On-line Feature Analysis}

The basic principles of on-line feature analysis as incorporated in this instrument have been published previously $/ 2 /$. The combination of feature size and shape analysis (based upon a video signal) with elemental typing from the X-ray spectrum provides more information about the sample than can normally be obtained from standard video-only techniques. In the TN-5500 system, the particle measurements procedures have been refined to accurately measure complex particulates, including fibers. In addition, feature analysis may be performed at high resolution directly from the microscope or at lower resolution from stored images when appropriate.

\section{Digital Stereo Microscopy}

The right and left-hand images of a stereo pair can be collected and stored as separate images and displayed side-by-side for viewing. A much more useful format can be obtained by combining both images digitally and displaying this image with a red and blue color transform. When viewed through glasses with corresponding red and blue filters, a 3-dimensional representation of the image can be seen on the video display. Feature 
height measurements can be obtained by the use of a dual red-blue cursor system. Height measurements are calculated using the tilt angle, magnification, and the parallax obtained from the position of the two cursors.

\section{Scanned TEM Imaging}

Several TEM/STEM systems have or can be fitted with post-specimen scan coils. By placing an aperture before the transmitted electron detector, and driving these coils with the digital scan generator, it is possible to digitize various types of TEM images, including diffraction patterns. These images may be enhanced as described earlier. Software is being developed to analyze collected diffraction patterns.

\section{ACKNOWLEDGMENTS}

The authors wish to acknowledge the assistance and collaboration of Dr. R. J. Lee and Dr. J. Walker of U. S. Steel Research Laboratories.

\section{REFERENCES}

1. McCARThy, J. 'J. and FERRARA, P. R., "On-Line Processing Digital SEM Images," Microbeam Analysis (1982) 118-120.

2. MCCARTHY, J. J., FISHER, R. M., and LEE, R. J., "Applications of Computers in Electron Microscopy," Ultramicroscopy $\underline{8}$ (1982) 351-360. 